\title{
Gender Identity Construction Through Traditional and Modern Lenses: Rwandan Narratives and MDGs Perspectives
}

\author{
Jean de Dieu Amini Ngabonziza ${ }^{1}$, Emmanuel Sibomana ${ }^{2}$, Epimaque Niyibizi ${ }^{3}$, Irenée Ndayambaje ${ }^{4}$ \\ ${ }^{1}$ University of Kibungo, Rwanda \\ ${ }^{2}$ The Wellspring Foundation for Education and University of Rwanda-College of Education, Rwanda \\ ${ }^{3}$ University of Rwanda - College of Education, Rwanda \\ ${ }^{4}$ Rwanda Education Board (REB), Rwanda \\ Correspondence: Emmanuel Sibomana, The Wellspring Foundation for Education and University of Rwanda-College of \\ Education, Rwanda.
}

Received: March 5, 2019

doi:10.11114/smc.v7i1.4347
Accepted: June 26, $2019 \quad$ Online Published: June 26, 2019

URL: https://doi.org/10.11114/smc.v7i1.4347

\begin{abstract}
While there is an on-going debate about what constitutes current policies and practices on gender equality between men and women in Rwanda, there is general agreement that Rwandan traditional beliefs and cultural norms have produced a patriarchy ideology and unequal power relations between women and men. Such traditional beliefs are not only observed in Rwanda, but in different parts of the world as well; and it is still problematic to assess a framework in which current gender policies are redesigned to allocate equitable power between women and men. This study focuses on the analysis and comparison of issues of gender identity and power relations as embedded in the Rwandan short narratives and in the Millennium Development Goals on gender equality. More specifically, this study investigates the design and redesign of the issues related to power relations and their effect on gender identity conception and assumption. Analysed from Marxist theories of power and Thompson's modes perspectives, the findings suggest that Rwandan traditional narratives view men as more powerful than women and the society expects more from men in terms of responsibilities. As for the Millennium Development Goals, they focus on women empowerment only and thereby create a new imbalance between men and women. The paper recommends equality in terms of a maleness and femaleness ideology from policy to legislation and other domains.
\end{abstract}

Keywords: gender, gender construction, Rwandan narratives, millennium development goals

\section{Introduction: Gender Identity From Global and Rwandan Perspectives}

From global perspectives, research on gender has divided the field of language and gender studies since the 1970s, with a particular focus on gender identity (Cameron 1985; Davies 1989; Wilshire 1989) power relations between men and women (Thompson 1990; Toubia 1994; Wajau \& Radeny 1994) and unequal power relations (Bourdieu 1991; Janks 2010; Janks et al. 2014), to cite just a few. In this regard, competing definitions of gender identity and issues around its construction have been so confusing that research on women, sex and language has adopted different positions on gender identity (Cameron 1985; Davies 1989). The divide line centers on whether the idea of being male or female, as identity, is biological or socially constructed. This binary understanding of sex has been a base of a number of policies designed to advocate for women's rights, equality, and justice (Rwanda Ministry of Gender and Family Promotion-MIGEPROF 2010; UN Millennium Development Goals 2000; UNICEF 2014). For instance, current policies in various countries, including Rwanda, are based on opposing traditions and culture construction of men dominance over women (MIGEPROF 2010; Toubia 1994; UN 2000). This can explain why Wajau and Radeny's (1994) research on gender and culture norms has shown that the patriarchy ideology has been a key factor to produce unequal power relations between males and females in Kenya and in other parts of the world. However, blaming culture norms for producing a patriarchy ideology without understanding the perspective from which it was designed would not contribute to projecting equity in gender identity treatment.

From the Rwandan perspective, MIGEPROF (2010) argues that the Rwandan cultural norms have shaped unequal power relations between men and women but the current ideological processes influencing current policies are striving 
to allocate the same power among human beings of both sexes. In other words, Rwanda wants to embrace new ideologies that are going to shape society in a way that brings about equity and equality of men and women. It is in this context that this paper aims at analysing those ideological processes that are embedded in the way Rwandan cultural norms have shaped unequal power relations between men and women through the lens of language. This lens has been used by pairing traditional Rwandan short narratives located in the Rwandan traditional cultural norms with the Millennium Development Goals (MDGs) located in the new ideologies. The justification for such pairing is that the traditional Rwandan short narratives constitute a local phenomenon, while Millennium Development Goals (MDGs) refer to an international and global program. Another rationale for analysing the Rwandan short narratives in comparison with the Millennium Development Goals is that such kind of analysis may help to locate possible changes in gender identity construction from the past to present and possible implications from a local or national perspective to a global perspective.

\section{Contextual background: Gender identity, language and power relations in Rwandan short narratives and in MDGs}

This study considers gender identities as socially (rather than biologically) constructed. These gender identities are analysed from the traditional Rwandan short narratives, which are crucial in displaying gender identity construction because they were shown to embody Rwandan values, beliefs and behaviours (Ngabonziza 2011). They are transmitted from generation to generation through orality or through oral literature as opposed to written literature (Niyibizi, Sibomana, Uwizeyemariya \& Niyomugabo, 2019). Such a phenomenon is not particular to Rwanda as various studies have shown that short narratives were used for the sake of a moral point and intended to teach (Barnet et al. 1961) in different parts of the world. In this regard, Njoroge (2009) argues that short traditional narratives are important in people's lives as they embrace the whole cultural structure of the Rwandan society and contain a common conscience and develop certain key cultural virtues such as love, courage and patience, as well as tolerance and kindness. Gender related issues occupy an important space in Rwandan traditional narratives and, therefore, are important to the Rwandan society. In this study, the analysis of gender identities was conducted on three traditional short narratives, which each of them being selected from one of the three types of Rwandan short narratives: satirical narratives, etiological narratives, and mysterious narratives (Ngabonziza 2011). These narratives are Nyirarunyonga, Amaco y'inda and Bagabo barabona.

The study also analysed gender identities in the Millennium Development Goals (MDGs), which are international development goals set by the world leaders in the Millennium Summit in September 2000 (UN 2000). During the summit, representatives from 189 United Nations member states agreed on their common destiny, where human development was emphasised as key to sustaining social and economic progress in all countries. To achieve this destiny, the leaders came up with eight goals as follows:

1. To eradicate extreme poverty and hunger

2. To achieve universal primary education

3. To promote gender equality and empower women

4. To reduce child mortality rates

5. To improve maternal health

6. To combat HIV/AIDS, malaria, and other diseases

7. To ensure environmental sustainability

8. To develop a global partnership for development (UN 2000; UNICEF 2014)

The leaders who established the above goals set 2015 as a deadline for the world to have achieved measurable improvements in the most critical areas of the human life (UNICEF 2014). Our study which focuses on gender identity construction based its analysis on various linguistic features related to gender and sex in this document. More specifically, the study zoomed into three of the above-mentioned Millennium Development Goals. These are Goal 2, 3, and 5 which have a particular focus on gender equality, its conception as well as its assumption towards power relations between women and men.

Having set the scene for this study, the investigation of the process of constructing gender relations builds on views from scholars like Wilshire (1989) and Davies (1994), who put forward the concept of being male or female as an identity, with distinguishing features, as summarised in Table 1 below: 
Table 1. Male/Female Binary, Adapted from Wilshire (1989) and Davies (1994)

\begin{tabular}{|c|c|}
\hline MALE & FEMALE \\
\hline Knowledge & Ignorance \\
\hline Higher up & Lower down \\
\hline Positive, good & Negative, bad \\
\hline Mind & Body \\
\hline Rational & Irrational \\
\hline Order & Chaos \\
\hline Control & Laissez faire \\
\hline Objective & Subjective \\
\hline Fact & Fiction \\
\hline Goals & Process \\
\hline Light & Dark \\
\hline Written text & Oral tradition \\
\hline Public domain & Private domain \\
\hline Detached & Attached \\
\hline Secular & Sacred \\
\hline Linear & Cyclical \\
\hline Permanence & Change \\
\hline Hard & Soft \\
\hline Independent & Dependent \\
\hline individual & Social \\
\hline Active & Passive \\
\hline
\end{tabular}

All these features that reflect gender identities and their power relations are expressed through language. That is why, from a social science perspective, language is defined as a medium of communication. This definition, however, does not do justice to the role of language in society and its "potential meaning" to a community (Halliday \& Hasan 1985). Recent studies (for example Ferris, Peck \& Banda 2013; Jaspal 2009; Val \& Vinogradova 2010) have shown that language is not a mere medium of communication but also a carrier of a set of societal values, the norms and beliefs of a given community. Language also embodies relations of power embedded in people's interactions (Gramsci 1985; Norton 2000). This study explores how language has been used to create gender identity and produce power relations through ideological processes. In order to investigate how language works to produce power relations and identity, this study applied it to the theories of power and identity, especially Marxist theories of power (Janks 2010, Janks et al. 2014) and Thompson's modes of operation of ideology (Thompson 1990), as described in the theoretical framework section below.

\section{Theoretical framework on gender identity and power relations}

This study was framed by Marxists theory of power and Thompson's modes of operation of ideology.

\section{Marxist theory of power}

Marxist theory of power (Janks 2010) broadly focuses on implications of power relations in social class relations and on the oppression of the working class. However, the same theory has been expanded to include other forms of power relations based on social formations such as gender, race, and ethnicity (Janks 2010). According to Gramsci (1985), the Marxist theory of power begins with the idea of classifying and ranking people. In this case, dominant groups get a superior status at expenses of others. Then, the so considered superior groups construct a discourse that justifies their domination and persuade subordinates to consent to their power (Gramsci 1985). Such domination, according to Janks et al. (2014), is emphasized by the naturalisation of power to dominant groups and common sense assumption to people represented as inferior. The strength of the Marxist theories of power is that it provides the starting point of demystifying social relations which implies power relations between people; its weakness resides in the fact that it does not provide ways of analysing how this powerful discourse works and the ways of struggling against it (Janks 2010; Janks et al. 2014). 


\section{Thompson's modes of operation of ideology}

The Thompson modes of operation of ideology, which were suggested by Thompson (1990) covers the weakness of the Marxist theories of power in the context that it provides ways of looking at how dominant discourse works to position subordinate groups and maintain the power of dominant groups. In these modes, Thompson (1990) explained ways in which language is used to construct identity and difference in the way people access power. He calls those ways "modes of operation of ideology" and these were later referred to as "Thompson's modes of operation of ideology". They are mainly based on the process of unifying and separating, which are key factors to constructing an identity. Thompson (1990) listed five modes from which we can analyse processes through which ideology is realized to maintain and justify power among people. These five modes are legitimization, dissimulation, unification, fragmentation, and reification. Thompson explains them as follows:

- Legitimization is the process by which power relations are affirmed to be just "by being presented as legitimate, that is, just and worth of support" (Thompson 1990:61). Thompson explains that legitimization is achieved by three discursive strategies: rationalization (by means of arguments), universalization (by presenting the interest of some as the interest of all), and narrativization (by means of narratives, myths and folk literatures).

- Dissimulation is the process by which the power relations are hidden from the general public. This is achieved through the use of euphemism and either renames oppressing terms or uses figurative language (displacement and trope).

- Unification and fragmentation are processes that concern with joining people for an ideological purpose (unification) or splitting people off from one another in order to rule (fragmentation). Although the two processes work in opposite directions, they are related in identity construction as fragmentation constructs others as different; unification constructs "us" as the same. It should be noted that both 'othering and sameness' are politically based ideologies, regardless of the human demographic situation and can be a source of conflicts, ethnic [as well as identity] based, depending on political will of its users (Ngabonziza 2014).

- Reification is a process of presenting a state of being as permanent, natural and timeless. According to Janks (2010), this process presents social, historical state of affairs as natural (naturalization), unchanged (externalization) as well as tenseless, with no agency and turning processes, verbs, things, names (nominalization and passivization).

The above Thompson's (1990) modes of operation of ideology with a support of Marxist theory of power (Janks 2010) have provided a framework to analyse the selected texts (Rwandan traditional narratives and MDGs) for this study. The combination of Marxist theory of power and Thompson's modes of operation of ideology helped to analyse gender construction from traditional to modern perspectives in a complementary way.: The weakness of the Marxist theory of power helped demystify the social relations, does not provide steps for analysing the power relations. In order to fill in this gap, we have applied Thompson's modes of operations of ideology which are used to analysed the power relation design through a construction of a powerful discourse. In this way, we have compared and contrasted traditional and modern constructions of power relation between men and women in the Rwanda society.

\section{Methodology}

In this study, the analysis was mainly guided by textual analysis. McKee (2005) argues that textual analysis allows an understanding of possible interpretations of texts by people who consume them, leading to implications of such interpretations. In fact, McKee (2005:1) continues, "when we perform textual analysis on a text, we make an educated guess at some of the most likely interpretations that might be made of a text". As Sibomana (201:96) suggests, texts are likely to enable various interpretations: the one(s) the writers expect readers to construct and the one(s) actually constructed by the reader(s). Using textual analysis, we could bring the likely implications of the different meanings of the analysed texts to the fore. As has been previously explained, the texts analysed in this study include both the traditional Rwandan short narratives related to gender and the Millennium Development Goals document. The texts were analysed with a focus on linguistic symbols used to construct and reconstruct gender identity. Thompson's (1990) modes of operational ideology were applied to a textual analysis of the Millennium Development Goals (UN 2000) and Traditional Rwandan short narratives (Njoroge 2009).

We have selected these two types of texts because they reflect two different ideologies as traditional texts with the modern texts, which are compared to show how gender identity was and is constructed from past to present. This may help to project the future design and construction of fair gender identity considering both traditional and modern concepts. In this case, three traditional Rwandan short narratives stand for past design while the three Millennium Development Goals represent the present design. As described in the background section, the three traditional Rwandan short narratives are Nyirarunyonga, Amaco y'inda and Bagabo barabona, which represent satirical narratives, 
etiological narratives, and mysterious narratives respectively (Ngabonziza 2011). As for the Millennium Development Goals, they are represented by Goal 2, to achieve universal primary education, Goal 3, to promote gender equality and empower women, and Goal 5, to improve maternal health. These three goals focus on gender equality, its conception as well its assumption towards power relations between women and men, as highlighted in the background section. They were analysed through 'lexicalisation' of gender and sex and 'overlexicalisation' that enabled to the construction of a female identity vis-à-vis a male identity.

\section{Findings}

This section discusses Gender identity construction through Traditional Rwandan short narratives and some of the Millennium Development Goals.

\section{Finding 1: Gender identity construction through Traditional Rwandan short narratives}

The analysis of the three traditional Rwandan short narratives led to the following findings in terms of gender identity construction, from the traditional perspectives:

Nyirarunyonga, the main character, in the Nyirarunyonga narrative, was a woman with strange behaviours, according to traditional norms, because she acted like a man. Several themes are discussed in the narratives about Nyirarunyonga but we will stick to the theme of a "satirical stories about a woman who behaves like a man".

The story starts narrating that one day, women observed a group of men who were chasing a buffalo in their village. After looking at how huge the buffalo was, they felt sorry and desperate for their husbands. Nyirarunyonga, one of the women observing the scene, laughed at them and told them that they had nothing to worry about their husbands because "Agakurikiwe n'abagabo ntikabasiga" which means that "men always succeed in whatever they are committed to do". While this story emphasises the dominance of men, with the proverb that recognize the courage of men, it makes women a subject of subordination to admire the dominance of men. Uncomfortable with the female identity, Nyirarunyonga distances herself from other women by laughing at them. Thus, she is both famous and a subject of criticism for acting irrespective of her female identity; she would also talk, believe, and act as men do. She was labelled as "Igishegabo" in Kinyarwanda (a woman who takes up men's roles - derogatory), which basically means a female who is committed to acting as (or even replace or rule over) men.

The second narrative, Amaco y'inda, is a mythical explanation of the reason why women should not eat "inyama y'ihene" (goat's meat) lest they grow beard. The story talks about a woman who ate goat's meat at night and the following day she was found with long beard. The story concludes by advising women to never eat goat's meat to avoid such a misfortune. This narrative refers to biological sex hormone differences as originating from the kind of food people eat. It draws a line that women should not cross regarding diet and, therefore, gives more rights to men than to women.

The third narrative is a mysterious one and it is a story of a man (Bagabobarabona) who lived on a hilltop near Byimana (one of the villages in Rwanda). When his wife became pregnant, she developed an obsessive urge to eat a special type of meal. For the first time, she wanted to eat "ikibirima" (a guinea fowl). Bagabobarabona went roaming the whole forest but could not find any guinea fowl. After many trials, his trap caught a tiny rat and it asked him to set it free and promised to save him in turn. Bagabobarabona set the rat free. The following day, a guinea fowl was caught. Bringing the fowl home, his journey was interrupted by a heavy downpour that forced him to seek shelter in a nearby rock. He first met a hungry hyena and then a leopard and a lion also came and all these beasts wanted to devour him. Fortunately, the tiny rat, which he set free from his trap, came and saved him in return (Rugamba 1987; Ngabonziza 2011). This narrative emphasises a positive relationship between a husband and wife although it subjects a man to making sacrifices to please his wife. From this narrative, it can be argued that while men are given more power, they are given greater responsibilities as well.

The above narratives share the representation of male and female identity as binary oppositions, as reflected in Table 1.1 in the contextual background section. They position men as legitimate heroes of the family (The Bagabo barabona narrative) and suggest that it may be shameful for a woman to want to do the same (in the case of the Nyirarunyonga narrative). This dichotomy might have originated from the patriarchy ideology which attributes more power to men than to women, as MIGEPROF (2010), Toubia (1994) and Wajau and Radeny (1994) suggested.

The distinction between the above narratives lies in the way the three narratives justify unequal power relations, rights and responsibilities between women and men. First, the above stories achieve their ideological purpose using narratives as timeless and appreciated norms to make men powerful and women powerless (Nyirarunyonga narrative and Amaco $y^{\prime}$ inda narrative). This is what Thompson (1990) views as legitimisation by means of narrativization. Second, the narratives show that even if traditional beliefs attribute more power to men, they also give them unfair consideration in responsibilities, which corroborates Janks et al.'s (2014:35) argument that “[...] with more power comes great 
responsibility" (see Bagabobarabona narrative). Even if the traditional norms give less power to women on the one hand, they provide them with more advantages on the other hand. In addition, it is important to highlight that traditional norms provide different roles to women and men based on construction of gender identity within male and female sex differences ability. Such attribution influences the understanding of their contribution to the society and provide unequal treatment to these two sexes. All these three narratives are viewed from the traditional lenses but our expectation is that the Millennium Development Goals (MDGs) look at both sides of the story to construct an equal and fair gender identity in terms of power relations, within the modern society.

\section{Finding 2: Gender identity construction through MDGs}

As highlighted in the contextual background and in the methodology sections, the analysis of gender identity construction focused on three Millennium Development Goals. These three goals emphasise gender equality in terms of education, health and women empowerment. The textual analysis of the three goals was done through 'lexicalisation' of gender and sex and 'overlexicalisation' that enabled to the construction of a female identity vis-à-vis a male identity. By 'lexicalisation', we refer to a process whereby different words are selected to construct the same idea differently while overlexicalization implies a situation where many words are used for the same phenomenon (Janks, 2005).

Analysing the 'lexicalisation' of gender and sex, we found that gender terms can be divided into three groups: female terms (women, girls, females, and maternal), male terms (boys, males, and paternal), and Neutral terms (population, children, personnel, slum dwellers, infant, youth, sex, and gender). While there is no problem with lexicalisation per se, there is an issue with 'overlexicalisation' to construct female identity when compared to the male identity. The 'overlexicalisation' illustrates who is the focus of the document and who benefits from the set goals. For instance, Goal 3 is "To promote gender equality and empower women." This gives women more power and prominence because 'promoting gender equality' would be enough and caters for both genders. However, if women need to be empowered on top of achieving gender equality, they get a special treatment. The analysis of the syntax concerning gender shows also that wording related to female identity appears most of the time on the first bit of clauses. The thematisation of female identity over male identity shows the shift from male focus to female focus. These linguistic features reveal how the Millennium Development Goals position women as more visible in society and dissimulate men's position that undermines theirs. This is reflected in Thompson's (1990) modes of operation of ideology, in its aspect of dissimulation. Even if this can be seen as a way of the needed shift from the patriarch ideology, this discourse tends to create a new imbalance between men and women instead of creating gender equality. Such imbalance is viewed as problematic by some, while it is seen as a positive shift of lenses by others, as discussed in the next section.

\section{Discussion}

The analysis of the traditional Rwandan short narratives and Millennium Development Goals revealed that both texts (traditional and modern) construct gender identity differently and provide unequal gender power relations. The traditional Rwandan short narratives use legitimation (Thompson 1990) to justify men dominance over women and construct male identity as naturally powerful. This is in line with the previous studies like Toubia (1994), Wajau and Radeny (1994), which demonstrated how the patriarchy ideology has produced unequal power relations between men and women by giving men more power than women. However, it is important to mention that the patriarchy was somehow unfair to men because it also gave them more responsibilities including protecting women and undergoing the most dangerous tasks for the safety of the whole family. This is illustrated by the third narrative, Bagabobarabona, whereby a husband nearly died for sake of his wife's happiness.

The Millennium Development Goals try to reverse the patriarchy ideology by constructing female identity as worth to be supported in order to access all key sectors of life (education, economic, politics, and health). However, the Millennium Development Goals hide the contribution and the rights of men and makes gender equality solely a women's business. By so doing, it makes male/female identity appear natural, timeless, agent-less and binary opposed, as highlighted in Wilshire (1989) and Davies's (1994) male/female binary (See Table 1). This illusive perspective gives the document the authority to claim the promotion of gender equality (MDG Goal 3) while emphasising women empowerment and never mentioning men's contribution to improving maternal health.

The fact that the document mentions women empowerment after gender equality makes the 'equality' problematic as only one side will be empowered (see Goal 3). This leads to more questions on gender issues: Who will benefit from the program that empowers women and leaves men behind? If the program aims at empowering women, what are the consequences on gender identity and power relations? While it may seem that the document gives more advantages to women, it does give also more critical disadvantages. The document uses dissimulation (Thompson 1990) to make women's interests more visible, which is positive. Nevertheless, it hides the working power that gives more power to men. In this regard, it is important to understand how a group becomes dominant at the expense of a subordinate group and the processes involved in changing equal power relations. 
According to Bourdieu (1991:57), unequal power relations start by "[...] unequal distribution of chances of access to the means of production of legitimate competence, and to the legitimate places of expression". In fact, the Millennium Development Goals emphasizes on providing more access to education, economic, leadership, and health for women (UNICEF 2014). However, the main issue is that while the document provides women with access to human development, it dissimulates the previous and working construction of power based on traditional norms. By so doing, the Millennium Development Goals fails to recognise that what is valued as powerful is socially constructed and it can be deconstructed in what Bourdieu (1991) called "symbolic power". That is, the male identity is only powerful because people give it that symbolic power as explained by the narratives analysed above. This failure of the Millennium Development Goals to design equal gender equality creates a new imbalance in power relations between women and men. Consequently, it maintains unchallenged male power and perpetuates a discourse of making women do as men to get a superior consideration.

The patriarchy ideology is at work in the Millennium Development Goals as it consents to male dominance, and gives more 'chances' to women which are only seen as 'catching up' with men. This correlates with Bourdieu's (1991) argument that this consent is ideologically manufactured as we saw it in the interpretation of the narratives by following Thompson's (1990) modes of operation of ideology. This argument tends to be in congruence with aforementioned Neo-Karl Marx's views that superior groups (men in this case) construct a discourse that justifies their power as natural and right to be supported. In this case, the 'to do as men do'discourse, is portrayed as a guaranteed pathway for women to reach their empowerment.

However, while, on the one hand, this may help women revolutionise their mind and think that they can achieve whatever men can, on the other hand, it limits a full potential of women to mimicking men's competence. Based on the findings of this study, it can be argued that a new design which can achieve true gender equality, the same case of the Millennium Development Goals, should also emphasise a discourse around gender identity in what Gee (1990) calls "ways of being in the world". This will create a fairer power relation that accepts other sex identity not as binary opposed but as a positive diversity resource which leads to social justice.

To achieve the social justice agenda, we need an understanding of inequality in power relation construction and deconstruction which, in this case, are concerned with identity positioning through social (re-)construction. The understanding of this identity construction process will enable a new policy design to lead people to understand and respect each other for social stability and help us to "[...] recognise that understanding and respecting difference are necessary for social stability" (Janks 2013:239). Hence, we should not replace one dominant discourse that constructs inequality based on gender differences by another one that essentially does exactly the same. We advocate a policy redesign that deconstructs both patriarchy ideology and matriarchy ideology and produces a more equitable society.

\section{Conclusion}

This paper applied a textual analysis to three traditional Rwandan short narratives and three Millennium Development Goals. The interpretation and discussions were done following Thompson's (1990) modes of operational ideology and Janks's (2010) Marxist theory of power. It also built on literature pertaining to the relationship between a language, discourse, identity and power relations. The key findings of this analysis indicate that traditional Rwandan narratives present men as more powerful than women and, therefore, more is expected of men in terms of responsibilities. In this regard, men have to take care of the needs of their families, including their wives. The analysis also suggests that the Millennium Development Goals promote equality between women and men in two challenging ways: on the one hand, the document focuses on gender equality and women empowerment in the main sectors of life namely education, health, economics, and leadership. On the other hand, by focusing on women empowerment only, the document creates new imbalance between men and women. The discussions illustrate a number of assumptions of the document including the idea of maleness and femaleness as binary opposites (opposed constructed identity). This study recommends that there is a need to understand ideologies from which the design of program is conceived as a starting point to redesign policies and legislation that benefit men and women equally.

\section{References}

Barnet, S. et al. (1961). An Introduction to Literature. (4th ed)., Little,Brown and Company Limited, Boston.

Bourdieu, P. (1991). Language and symbolic power. Polity Press, Cambridge.

Davies, B. (1989). Frogs and snails and feminist tales. Allen and Unwin, Sydney.

Davies, B. (1994). Poststructuralist theory and classroom practice. Deakin University, Geelong, VIC

Ferris, F. S., Peck, A., \& Banda, F. (2013). Identity. In Z. Bock \& G. Mheeta (Eds), Language, Society and Communication. Van Schaick Publishers, Pretoria. 
Gee, J. P. (1990). Social Linguistics and Literacies: Ideology in Discourses, $1^{\text {st }}$ Ed. The Falmer Press, London

Gramsci, A. (1985). Solution from cultural writings. In T. Crowley (ed.), The Politics of Discourse: The Standard Language Question in British Cultural Debates, Macmillan, Basingstoke.

Halliday, M. A. K., \& Hasan, R. (1985). Language, Context and Text: Aspects of Language in a Social Semiotic Perspective. Deakin University, Victoria.

Janks, et al., (2014). Doing critical literacy: Texts and activities for students and teachers. Routledge, London, England. https://doi.org/10.4324/9780203118627

Janks, H. (2005). Language and design of text. English Teaching: Practice and Critique, 4(3), 97-110.

Janks, H. (2010). Literacy and Power. Routledge, London, England. https://doi.org/10.4324/9780203869956

Janks, H. (2013). Critical literacy in teaching and research. Education Inquiry, 4(2), 225-242. https://doi.org/10.3402/edui.v4i2.22071

Jaspal, R. (2009). Language and social identity: A psychosocial approach. Psych-Talk, 17-20.

McKee, A. (2005). Textual analysis: a beginner's guide. London, California, New Delhi: Sage Publications Ltd.

MIGEPROF. (2010). National gender policy. Retrieved on $30^{\text {th }}$ January, 2018 from http://www.gmo.gov.rw/uploads/media/NGP-FINAL_VERSION_02_JULY_2010.pdf

Ngabonziza, A. J. (2011). The importance of Rwandan short story in teaching English as a foreign language. Unpublished bachelor's thesis, National University of Rwanda.

Ngabonziza, A. J. (2015). Space (re)design (im) possibilities: An analysis of a spatial literacy project-a critical literacy perspective, INATEK Scientific journal, 6(1), 1-10

Niyibizi, E., Sibomana, E., Uwizeyemariya, A., Ntabajyana, S., \& Niyomugabo, C. (2019). Teacher Education Through Flexible Learning, 1(1), 1-24.

Njoroge, T. (2009). From the heart of Africa Short stories from Rwanda. Multicom Printing \& Publishing, Kigali.

Norton, B. (2000). Identity and Language Learning: Gender, Ethnicity and Educational Change. Longman, Harlow, England

Rugamba, C. (1987). Ngucire umugani ( $1^{\text {st }}$ Ed.). Institut National de Recherche Scientifique, Butare, Rwanda.

Sibomana, E. (2015). The role of distance education materials in addressing the professional development needs of high school English teachers in Rwanda. Doctoral dissertation, University of the Witwatersrand, Johanesburg.

Thompson, J. B. (1990). Ideology and modern culture. Basil Blackwell, Oxford

Toubia, N. (1994). Female genital mutilation and the responsibility of reproductive health professionals. International Journal of Gynaecology and Obstetrics, 46, 127-135. https://doi.org/10.1016/0020-7292(94)90227-5

UN, United Nations. (2000). United Nations Millennium. Retrieved from http://www.un.org/en/ga/search/view_doc.asp?symbol=A/RES/55/2

UNICEF. (2014). Millennium Development Goals. Retrieved on 10 October, 2018 from www.unicef.org/Rwanda/Rwa_official_efareview 2014.pdf.

Val, A., \& Vinogradova, P. (2010). What is the identity of a heritage language speaker? Heritage Briefs. Retrieved from http://www.cal.org/heritage/pdfs/briefs/what-is-theidentity-of-a-heritage-language-speaker.pdf, on 07 March 2016

Wajau, W., \& Radeny, S. (1994). Sexuality among Adolescent in Kenya. Kenya Association for the Promotion of Adolescent health, Nairobi.

Willshire, D. (1989). The use of myth, Image and the female Body in Revisioning Knowledge. Rutgers University Press, New Brunswick.

\section{Copyrights}

Copyright for this article is retained by the author(s), with first publication rights granted to the journal.

This is an open-access article distributed under the terms and conditions of the Creative Commons Attribution license which permits unrestricted use, distribution, and reproduction in any medium, provided the original work is properly cited. 